\title{
Retrospective Study of Nephrotoxicity Rate among Adult Patients Receiving Colistin Compared to $\beta$-lactam Antibiotics
}

\author{
Abdul Ghafur ${ }^{1}$, Nitin Bansal ${ }^{2}$, Vidyalakshmi Devarajan ${ }^{3}$, T Raja $^{4}$, Jose Easow ${ }^{5}$, MA Raja $^{6}$, Sankar Sreenivas ${ }^{7}$, \\ Balasubramaniam Ramakrishnan ${ }^{8}$, SG Raman ${ }^{9}$, Dedeepiya Devaprasad ${ }^{10}$, Ramesh Nimmagadda ${ }^{11}$
}

\begin{abstract}
Purpose: Patients receiving colistin for carbapenem-resistant gram-negative bacteria (CR-GNB) infections generally have multiple risk factors for nephrotoxicity, so it might be possible that colistin may be erroneously blamed for the nephrotoxicity.

Materials and methods: We retrospectively analyzed case records of patients who received colistin and those who received antibiotics other than colistin [carbapenem or $\beta$-lactam- $\beta$-lactamases inhibitors ( $\beta L-\beta L I)$ ] for gram-negative bacteremia. Those patients with preexisting renal failure and those who received antibiotics for $<72$ hours were excluded from the study. Nephrotoxicity was assessed using the risk of renal dysfunction, injury to the kidney, failure of kidney function, loss of kidney function, end-stage kidney disease (RIFLE) criteria.

Results: Out of the 222 patients, the colistin arm had 118 and the noncolistin arm had 104 patients. Even though the colistin arm had significantly higher number of sicker patients with neutropenia ( $40.7 \%$ vs $14.4 \%, p=0.0001)$, mechanical ventilation $(0.0001)$, having lines $(0.0001)$, on inotropes (0.003), receiving other nephrotoxic drugs $(0.0001)$, and higher Pitt score $(p=0.0001)$, there was no significant difference in the nephrotoxicity between the two arms $(10.2 \%$ vs $9.6 \%, p=0.89)$. Logistical regression showed a higher Pitt bacteremia score $(p=0.03)$ and a higher Charlson comorbidity index $(p=0.02)$, but not colistin administration $(p=0.32)$, were independently associated with nephrotoxicity. Conclusion: Administration of colistin was not associated with higher rates of nephrotoxicity than carbapenems or $\beta L-\beta L I$ agents.

Keywords: Carbapenem resistance, Colistin nephrotoxicity, Risk of renal dysfunction, injury to the kidney, failure of kidney function, loss of kidney function, end-stage kidney disease score.

Indian Journal of Critical Care Medicine (2019): 10.5005/jp-journals-10071-23276
\end{abstract}

\section{INTRODUCTION}

Global dissemination of CR-GNB has resulted in a significant increase in the usage of colistin and the situation is no different in India. ${ }^{1,2}$ Nephrotoxicity has always been a concern with use of colistin. Traditionally, colistin per se is considered to be the culprit for nephrotoxicity. Unfortunately, contribution of colistin toward the nephrotoxicity has not been studied in well-controlled properly matched trials. Colistin is generally used in patients who are critically ill with various stages of sepsis, including septic shock. Patients receiving colistin are generally sicker, with multiple other risk factors for nephrotoxicity such as severe sepsis and coadministration of other nephrotoxic drugs. Acute kidney injury (AKI) is common in sepsis and is independent of the drugs used to treat sepsis. ${ }^{3}$ So, it is possible that the nephrotoxicity rate of colistin is overestimated. There is a remarkable variation in the reported rates of nephrotoxicity associated with colistin use (0-53\%), due to lack of proper definition of nephrotoxicity, proper control group, and unmatched risk factors. ${ }^{4}$ The concern of nephrotoxicity leads to underdosing of colistin that in turn leads to poor outcomes and colistin resistance. So, it is need of the hour to delineate the nephrotoxicity risk due to colistin usage per se, in critically ill patients where other contributing factors including concomitant nephrotoxic drugs are used. With this aim, we designed our study to assess the risk of nephrotoxicity, as defined by the RIFLE classification system, ${ }^{5}$ in patients receiving colistin while compared to those not receiving colistin.

\section{Materials and Methods}

This was a retrospective study done in an oncology center in South India. We analyzed medical records of patients with GNB bacteremia $\overline{1,2,3 \text { Department of Infectious Diseases and Clinical Microbiology, }}$ Apollo Cancer Institute, Chennai, Tamil Nadu, India

4,6,7,9,11 Department of Medical Oncology, Apollo Cancer Institute, Chennai, Tamil Nadu, India

${ }^{5}$ Department of Oncohematology, Apollo Cancer Institute, Chennai, Tamil Nadu, India

${ }^{8}$ Department of Statistics, Apollo Cancer Institute, Chennai, Tamil Nadu, India

${ }^{10}$ Department of Critical Care, Apollo Cancer Institute, Chennai, Tamil Nadu, India

Corresponding Author: Nitin Bansal, Department of Infectious Diseases and Clinical Microbiology, Apollo Cancer Institute, Chennai, Tamil Nadu, India, Phone: +91 9711737508, e-mail: nitin.bansal3011@ gmail.com

How to cite this article: Ghafur A, Bansal N, Devarajan V, Raja T, Easow J, Raja MA, et al. Retrospective Study of Nephrotoxicity Rate among Adult Patients Receiving Colistin Compared to $\beta$-lactam Antibiotics. IJCCM 2019;23(11):518-522.

Source of support: Part of the data was sourced from the colistinbased combination therapy study we did earlier, utilizing educational grants from AstraZeneca and Glenmark pharmaceuticals. Grant providers had no role in the study design, data collection, analysis, or paper writing.

Conflict of interest: All the authors have seen the final manuscript and approve it for submission. Abdul Ghafur has received advisory fee, lecture fees, or consultancy fees from Cipla, Biomerioux, Glenmark, Astellas, Sun Pharma, Pfizer, MSD, and Abbott. Some of these companies manufacture colistin. Other authors have no competing interests in the publication of this manuscript to declare.

o The Author(s). 2019 Open Access This article is distributed under the terms of the Creative Commons Attribution 4.0 International License (https://creativecommons. org/licenses/by-nc/4.0/), which permits unrestricted use, distribution, and non-commercial reproduction in any medium, provided you give appropriate credit to the original author(s) and the source, provide a link to the Creative Commons license, and indicate if changes were made. The Creative Commons Public Domain Dedication waiver (http://creativecommons.org/publicdomain/zero/1.0/) applies to the data made available in this article, unless otherwise stated. 
who received colistin or antibiotics other than colistin (carbapenem or $\beta L-\beta L I)$ during period of January 2014-July 2017.

Only those patients of age $\geq 18$ years who received antibiotics for $\geq 72$ hours were included in the study. Patients with preexisting renal failure or chronic kidney disease and those who received antibiotics for $<72$ hours were excluded. Demographic details, underlying diagnosis, concomitant use of other nephrotoxic agents (amphotericin B, aminoglycosides, cyclosporine, acyclovir, vancomycin, cyclophosphamide, methotrexate, cisplatin, nonsteroidal anti-inflammatory medications, diuretics, and intravenous contrast), and dose and duration of colistin were collected. Creatinine values before initiation of colistin, during, and at the end of treatment were tracked. Nephrotoxicity was assessed using the RIFLE criteria.

Patients were divided into colistin and noncolistin groups. Patients who received colistin alone or in combination with other antibiotic were included in the colistin arm, whereas, those patients who received antibiotics other than colistin (carbapenem or $\beta L-\beta L I$ ) were included in the noncolistin arm. Comparative analyses of various parameters, univariate and multivariate logistic regression analysis, using abnormal RIFLE as the dependent variable were performed using SPSS 25.0. All $p$ values $<0.05$ were considered as statistically significant.

\section{Results}

A total of 222 patients met the inclusion criteria and their records were analyzed. The colistin arm had 118 patients and the noncolistin arm had 104 patients (Table 1). In the noncolistin arm, 80 patients received cefoperazone-sulbactam and 24 patients received meropenem. Patients in the colistin arm were significantly younger than in noncolistin arm ( $44.6 \pm 18.2$ vs $51.6 \pm 18.9$ years; $p=0-005)$. There was no significant difference in distribution of gender between the two arms. Patients belonging to the colistin arm were more likely to have hematological (49/118 vs $23 / 104$; $p<0.05)$ and neurosurgical (29/118 vs $2 / 104 ; p<0.05)$ conditions as their basic disease compared to patients in the noncolistin arm; whereas solid organ malignancies were more common in the noncolistin arm (33/118 vs 65/104; $p<0.05)$.

Pneumonia (21/118 vs $10 / 104 ; p<0.05)$, meningitis $(4 / 118$ vs $0 / 104 ; p<0.05)$, skin/soft tissue infection $(3 / 118$ vs $2 / 104$; $p<0.05)$, line-related bacteremia (17/118 vs 7/104; $p<0.05)$, and gut translocation $(36 / 118 \mathrm{vs} 21 / 104 ; p<0.05)$ as the source of bacteremia were significantly higher in the colistin arm as compared to the noncolistin arm. Intra-abdominal infection (9/118 vs 32/104; $p<0.05)$, urinary tract infection $(16 / 118$ vs $32 / 104 ; p<0.05)$, and unknown focus $(10 / 118$ vs $10 / 104 ; p<0.05)$ as the source of bacteremia were significantly higher in the noncolistin arm.

Distribution of comorbidities like diabetes mellitus, hypertension, chronic liver disease, and heart failure was comparable between the two arms. Presence of an immunocompromised state (60/118 vs $13 / 104 ; p<0.05)$, mechanical ventilation (61/118 vs $19 / 104 ; p<0.05)$, neutropenia (48/118 vs $15 / 104 ; p<0.05)$, central lines $(59 / 118$ vs $20 / 104 ; p<0.05)$, urinary catheter (40/118 vs $11 / 104$; $p<0.05)$, surgery (48/118 vs $11 / 104 ; p<0.05)$, admission in critical care unit at the time of bacteremia ( $71 / 118$ vs $16 / 104 ; p<0.05)$, and inotropic requirement $(40 / 118$ vs $17 / 104 ; p<0.05)$ was significantly higher in the colistin arm as compared to the noncolistin arm. Use of chemotherapeutic agents and diuretics was comparable in both arms. Significantly more number of patients in the colistin arm
Table 1: Distribution of various variables of the two study groups

\begin{tabular}{|c|c|c|c|}
\hline Categories & $\begin{array}{l}\text { Colistin arm } \\
(n=118)\end{array}$ & $\begin{array}{l}\text { Noncolistin } \\
\operatorname{arm}(n=108)\end{array}$ & $p$ value \\
\hline Age (mean $\pm 2 S D$ ) in years & $44.6+18.2$ & $51.6+18.9$ & 0.005 \\
\hline Male $n(\%)$ & $72(61)$ & $52(50)$ & 0.099 \\
\hline \multicolumn{4}{|l|}{ Basic diagnosis } \\
\hline Hematological $n(\%)$ & $49(41.5)$ & $23(22.1)$ & 0.0001 \\
\hline Neurosurgical $n(\%)$ & $29(24.6)$ & $2(1.9)$ & \\
\hline Solid tumors $n$ (\%) & $33(28)$ & $65(62.5)$ & \\
\hline Others $n(\%)$ & $7(5.9)$ & $14(13.5)$ & \\
\hline \multicolumn{4}{|l|}{ Source of bacteremia } \\
\hline Meningitis $n(\%)$ & $4(3.4)$ & 0 & 0.0001 \\
\hline Pneumonia $n(\%)$ & $21(17.8)$ & $10(9.6)$ & \\
\hline $\begin{array}{l}\text { Intra-abdominal infection } \\
n(\%)\end{array}$ & $9(7.6)$ & $32(30.8)$ & \\
\hline Urinary tract infection $n(\%)$ & $16(13.6)$ & $22(21.2)$ & \\
\hline Soft tissue infection $n(\%)$ & $3(2.5)$ & $2(1.9)$ & \\
\hline Gut translocation $n(\%)$ & $36(30.5)$ & $21(20.2)$ & \\
\hline Central line $n(\%)$ & $17(14.4)$ & $7(6.7)$ & \\
\hline Unknown source $n(\%)$ & $10(8.5)$ & $10(9.6)$ & \\
\hline \multicolumn{4}{|l|}{ Risk factors } \\
\hline $\mathrm{DM} n(\%)$ & $33(28)$ & $38(36.5)$ & 0.172 \\
\hline HTN $n(\%)$ & $34(28.8)$ & $29(27.9)$ & 0.878 \\
\hline CLD $n(\%)$ & $2(1.7)$ & 0 & 0.5 \\
\hline CHD $n(\%)$ & $8(6.8)$ & $7(6.7)$ & 0.988 \\
\hline IMC $n(\%)$ & $60(50.8)$ & $13(12.5)$ & 0.0001 \\
\hline Neutropenia $n(\%)$ & $40(40.7)$ & $15(14.4)$ & 0.0001 \\
\hline Mechanical ventilation $n(\%)$ & $61(51.7)$ & $19(18.3)$ & 0.0001 \\
\hline Central line $n(\%)$ & $59(50)$ & $22(21.2)$ & 0.0001 \\
\hline Urinary catheter $n(\%)$ & $40(33.9)$ & $11(10.6)$ & 0.0001 \\
\hline $\begin{array}{l}\text { ICU admission during } \\
\text { bacteremia } n(\%)\end{array}$ & $71(61.2)$ & $16(15.4)$ & 0.0001 \\
\hline Chemotherapy $n$ (\%) & $44(37.3)$ & $33(31.7)$ & 0.385 \\
\hline Surgery $n(\%)$ & $48(40.7)$ & $11(10.6)$ & 0.0001 \\
\hline Diuretics n (\%) & $31(26.3)$ & $20(19.2)$ & 0.213 \\
\hline Inotropes n (\%) & $40(33.9)$ & $17(16.3)$ & 0.003 \\
\hline Nephrotoxic drugs (\%) & $31(26.3)$ & $8(7.7)$ & 0.0001 \\
\hline APACHE score (mean $\pm 2 \mathrm{SD})$ & $20.2+7.3$ & $17 \pm 7.6$ & 0.044 \\
\hline $\begin{array}{l}\text { Charlson comorbidity index } \\
\text { (mean } \pm 2 \mathrm{SD})\end{array}$ & $4.7+2.9$ & $4.6+2.7$ & 0.721 \\
\hline $\begin{array}{l}\text { Pitt bacteremia score } \\
(\text { mean } \pm 2 S D)\end{array}$ & $3.2+2.2$ & $1.9+1.9$ & 0.0001 \\
\hline \multicolumn{4}{|l|}{ Outcomes } \\
\hline $\begin{array}{l}\text { All-cause mortality at } \\
30 \text { days } n(\%)\end{array}$ & $39(33.1)$ & $20(19.2)$ & 0.02 \\
\hline Abnormal RIFLE $n(\%)$ & $12(10.2)$ & $10(9.6)$ & 0.89 \\
\hline
\end{tabular}

received other nephrotoxic agents as compared to the non-colistin $\operatorname{arm}(31 / 118$ vs $8 / 104 ; p<0.05)$.

The mean dose, mean duration, and cumulative dose of colistin used were $8.54 \pm 1.08$ million units/day, $8.10 \pm 4.63$ days, and 69.02 million units, respectively. Patients in the colistin arm had significantly higher acute physiology, age, chronic health evaluation (APACHE) $(20.7 \pm 7.3$ vs $17 \pm 7.6, p=0.04)$ and Pitt bacteremia $(3.2 \pm 2.2$ vs $1.9 \pm 1.9 ; p<0.05)$ scores in comparison to those 
in the non-colistin arm. The Charlson comorbidity index was not significantly different between the two groups. Distribution of patients with abnormal RIFLE was not significantly different between the two groups (12/118 vs $10 / 104 ; p=0.89$ ). At 30 days, significantly higher number of patients died in the colistin arm as compared to the noncolistin arm (39/118 vs $20 / 104 ; p=0.02)$.

On univariate logistic regression analysis, male sex $(\mathrm{OR}=3.5$; $95 \% \mathrm{Cl}=1.05-11.65, p=0.04)$, and the higher Charlson comorbidity index of $\geq 4(\mathrm{OR}=8.64 ; 95 \% \mathrm{Cl}=1.63-45.57 ; p=0.01)$ were associated with abnormal RIFLE. On multivariate logistic regression analysis, higher Pitt bacteremia score of $\geq 3(\mathrm{OR}=3.35 ; 95 \% \mathrm{Cl}=1.11-9.91$; $p=0.03)$ and higher Charlson comorbidity index of $\geq 4(\mathrm{OR}=5.52$; $95 \% \mathrm{Cl}=1.11-9.91 ; p=0.02$ ) were the only variables independently associated with nephrotoxicity (Table 2). Other parameters like diabetes, age, hypertension, and use of nephrotoxic drugs were not independent risk factors for the development of abnormal RIFLE. Colistin administration per se was not an independent risk factor for nephrotoxicity $(p=0.32)$.

\section{Discussion}

Though the conundrum of monotherapy vs combination therapy is not yet resolved, colistin is undoubtedly the backbone of the therapeutic approach against CR-GNB infections. ${ }^{6}$ Colistin, a drug introduced in 1960s, later went out of use in 1970s due to its high rate of nephrotoxicity and due to the availability of newer and less nephrotoxic drugs. ${ }^{7}$ Global dissemination of CR-GNB has helped colistin to attain the status of an indispensable agent in critical care units. Reported rates of nephrotoxicity vary widely (0-60\%) among studies. ${ }^{8,9}$ Variability in the criteria used to define nephrotoxicity could be one of the reasons behind this. Compared to older studies, more recent ones report lower rates of nephrotoxicity. This could be due to less impurities present in the newer colistin preparations and better understanding of fluid management strategies in septic patients in modern intensive care units. ${ }^{4,10-12}$ The nephrotoxicity rate in a recently published study from our own center was $13.3 \% .^{12}$
Concomitant use of vancomycin, abnormal baseline creatinine, ICU stay, and higher disease severity were associated with higher rates of nephrotoxicity in patients on colistin. ${ }^{12}$

Sepsis per se is a well-defined independent risk factor for the development of $\mathrm{AKI}^{3}$ Acute kidney injury develops in $51 \%$ of patients having septic shock with blood culture positivity. ${ }^{3} \mathrm{Gram}$ negative sepsis has been proven to be an independent risk factor of AKI in ICUs. ${ }^{13}$ Proinflammatory cytokines are released on exposure to lipopolysaccharide, leading to intrarenal vasoconstriction and a reduction in the glomerular filtration rate. ${ }^{14}$ Sepsis and gramnegative bacteremia, two factors independently associated with the development of AKI, are present in most patients receiving colistin.

Exact mechanism of nephrotoxicity is not known but polymyxins cause damage to kidneys at the level of proximal tubules and can be directly toxic to mammalian urothelium. ${ }^{15}$ One of the main reasons for the wide variability in the rates of nephrotoxicity is the difference in definition of renal failure used in various studies. The RIFLE criteria detect AKI with high sensitivity and high specificity and also predict prognosis of the patients. ${ }^{5}$ Most studies reporting high colistin nephrotoxicity rates had methodological defects such as absence of control groups and not considering sepsis and its severity as potential confounding factors. ${ }^{16-19}$ Acute kidney injury is common in septic shock and it may potentiate or lead to overestimation of nephrotoxicity rates of any drug. ${ }^{20}$ A study done by Rocco et al. reported that the onset of AKI was two times more likely with SAPS II scores $\geq 44$ and six times more likely with presence of septic shock at infection onset and was independent of colistin use. ${ }^{21}$ A meta-analysis on six controlled studies comparing colistin vs other antibiotics for treatment of ventilator associated pneumonia (VAP) suggested that the nephrotoxicity rate for colistin was similar to that in the control group. ${ }^{22}$ As per the NEFROINT multicenter study from Italy, $40 \%$ of the patients admitted to ICU with a normal renal function at the time of admission developed AKI regardless of whether or not nephrotoxic drugs were administered. ${ }^{23}$ However, a large single-center prospective cohort study from Israel reported

Table 2: Univariate and multivariate regression analysis between normal and abnormal RIFLE

\begin{tabular}{|c|c|c|c|c|c|c|}
\hline \multirow[b]{2}{*}{ Variables } & \multicolumn{3}{|c|}{ Univariate analysis } & \multicolumn{3}{|c|}{ Multivariate analysis } \\
\hline & Odds ratio & $\begin{array}{l}95 \% \text { confidence } \\
\text { interval }\end{array}$ & $p$ value & Odds ratio & $\begin{array}{l}95 \% \text { confidence } \\
\text { interval }\end{array}$ & $p$ value \\
\hline Sex & 3.50 & $1.05-11.65$ & 0.04 & 2.75 & $0.93-8.10$ & 0.066 \\
\hline ICU admission during bacteremia & 1.43 & $0.37-5.47$ & 0.60 & & & \\
\hline DM & 1.93 & $0.56-6.64$ & 0.29 & & & \\
\hline HTN & 0.38 & $0.10-1.39$ & 0.14 & 0.41 & $0.13-1.27$ & 0.12 \\
\hline IMC & 1.49 & $0.39-5.69$ & 0.55 & & & \\
\hline Chemotherapy & 0.51 & $0.14-1.86$ & 0.31 & & & \\
\hline Surgery & 2.05 & $0.44-9.47$ & 0.35 & & & \\
\hline Neutropenia & 0.90 & $0.23-3.51$ & 0.88 & & & \\
\hline Diuretics & 2.24 & $0.59-8.49$ & 0.23 & 2.62 & $0.67-7.59$ & 0.18 \\
\hline Nephrotoxic drugs & 1.61 & $0.33-7.83$ & 0.55 & & & \\
\hline Inotropes & 0.46 & $0.11-1.83$ & 0.27 & & & \\
\hline Central line & 0.64 & $0.21-1.98$ & 0.44 & & & \\
\hline Urinary catheter & 1.50 & $0.37-6.38$ & 0.56 & & & \\
\hline Colistin/noncolistin & 1.22 & $0.32-4.57$ & 0.76 & 0.59 & $0.20-1.69$ & 0.32 \\
\hline Charlson comorbidity index & 8.64 & $1.6-45.57$ & 0.01 & 5.52 & $1.26-24.09$ & 0.02 \\
\hline Pitt bacteremia score & 2.35 & $0.53-10.27$ & 0.25 & 3.32 & $1.11-9.91$ & 0.03 \\
\hline Age & 0.41 & $0.10-1.70$ & 0.22 & 0.41 & $0.11-1.41$ & 0.17 \\
\hline
\end{tabular}


higher nephrotoxicity in the colistin arm compared to patients receiving $\beta$-lactam antibiotics. ${ }^{24}$

In our study, the rate of kidney injury in the colistin arm was $10.2 \%$, marginally lower than an earlier report (13.3\%) from our own center and rather lower in comparison to the $16-35 \%$ reported in other Indian studies. ${ }^{8,12,25,26}$ None of these studies, including our own earlier one, had a comparative arm with patients not receiving colistin. To the best of our knowledge, this is the first study from India comparing the nephrotoxicity in patients receiving colistin to those not receiving colistin. Even though patients in the colistin arm were sicker, with higher APACHE and Pitt bacteremia scores, greater number of patients with neutropenia, and on mechanical ventilation, nephrotoxicity was not significantly different in both arms (10.2\% vs $9.6 \%, p=0.89)$ indicating that colistin administration doesn't increase the nephrotoxicity risk compared to carbapenem or $\beta \mathrm{L}-\beta \mathrm{LI}$ agents. On logistic regression analysis, higher Charlson comorbidity index and Pitt bacteremia score were the only independent variables for abnormal RIFLE. Colistin administration was not independently associated with the development of abnormal RIFLE, despite receiving the current dosing recommendation of 9 million a day. The result of our study should encourage clinicians to administer the recommended colistin dose, without any fear of nephrotoxicity. Major limitation of our study is its retrospective single-center design. Inclusion of a comparator arm and a large cohort of patients should be considered strengths of this study. Prospective randomized controlled trials are need of the hour.

\section{ConcLusion}

In our single-center retrospective comparative cohort study, there was no statistically significant difference in nephrotoxicity in patients receiving colistin compared to those who received a $\beta$-lactam antibiotic such as a $\beta L-\beta L I$ agent or carbapenem. Higher Pitt bacteremia score and Charlson comorbidity index were independent risk factors for the development of abnormal RIFLE. Colistin administration was not independently associated with nephrotoxicity.

\section{References}

1. Xu Y, Gu B, Huang M, Liu H, Xu T, Xia W, et al. Epidemiology of carbapenem resistant Enterobacteriaceae (CRE) during 2000-2012 in Asia. J Thorac Dis 2015;7(3):376-385. DOI: 10.3978/j.issn.20721439.2014.12.33.

2. Hsu L-Y, Apisarnthanarak A, Khan E, Suwantarat N, Ghafur A, Tambyah PA. Carbapenem-resistant Acinetobacter baumannii and Enterobacteriaceae in South and Southeast Asia. Clin Microbiol Rev 2017;30(1):1-22. DOI: 10.1128/CMR.00042-16.

3. Rangel-Frausto MS, Pittet $D$, Costigan M, Hwang T, Davis CS, Wenzel RP. The natural history of the systemic inflammatory response syndrome (SIRS): a prospective study. JAMA 1995;273(2):117-123. DOI: $10.1001 /$ jama.1995.03520260039030.

4. Spapen H, Jacobs R, Van Gorp V, Troubleyn J, Honoré PM. Renal and neurological side effects of colistin in critically ill patients. Ann Intensive Care 2011;1(1):14. DOI: 10.1186/2110-5820-1-14.

5. Bellomo R, Ronco C, Kellum JA, Mehta RL, Palevsky P, the Acute Dialysis Quality Initiative Workgroup. Acute renal failure - definition, outcome measures, animal models, fluid therapy and information technology needs: the Second International Consensus Conference of the acute dialysis quality initiative (ADQI) group. Crit Care 2004;8(4):R204-R212. DOI: $10.1186 / \mathrm{cc} 2872$.

6. Gutiérrez-Gutiérrez B, Salamanca E, de Cueto M, Hsueh PR, Viale $P$, Paño-Pardo JR, et al. Effect of appropriate combination therapy on mortality of patients with bloodstream infections due to carbapenemase-producing Enterobacteriaceae (INCREMENT): a retrospective cohort study. Lancet Infect Dis 2017;17(7):726-734. DOI: 10.1016/S1473-3099(17)30228-1.

7. Li J, Nation RL, Turnidge JD, Milne RW, Coulthard K, Rayner CR, et al. Colistin: the re-emerging antibiotic for multidrug-resistant Gram negative bacterial infections. Lancet Infect Dis 2006;6(9):589-601. DOI: 10.1016/S1473-3099(06)70580-1.

8. Doshi NM, Mount KL, Murphy CV. Nephrotoxicity associated with intravenous colistin in critically ill patients. Pharmacotherapy 2011;31(12):1257-1264. DOI: 10.1592/phco.31.12.1257.

9. Falagas ME, Rafailidis PI, loannidou E, Alexiou VG, Matthaiou DK, Karageorgopoulos DE, et al. Colistin therapy for microbiologically documented multidrug-resistant Gram-negative bacterial infections: a retrospective cohort study of 258 patients. Int J Antimicrob Agents 2010;35(2):194-199. DOI: 10.1016/j.jijantimicag.2009.10.005.

10. Cheng CY, Sheng WH, Wang JT, Chen YC, Chang SC. Safety and efficacy of intravenous colistin (colistin methanesulphonate) for severe multidrug resistant Gram-negative bacterial infections. Int J Antimicrob Agents 2010;35(3):297-300. DOI: 10.1016/ j.jjantimicag.2009.11.016.

11. Kim J, Lee K-H, Yoo S, Pai H. Clinical characteristics and risk factors of colistin-induced nephrotoxicity. Int J Antimicrob Agents 2009;34(5):434-438. DOI: 10.1016/j.jijantimicag.2009.06.028.

12. Ghafur A, Gohel S, Devarajan V, Raja T, Easow J, Raja MA, et al. Colistin nephrotoxicity in adults: single center large series from India. Indian J Crit Care Med 2017;21(6):350-354. DOI: 10.4103/ijccm.IJCCM_ 140_17.

13. Lopes JA, Jorge S, Resina C, Santos C, Pereira A, Neves J, et al. Acute renal failure in patients with sepsis. Crit Care 2007;11(2):411. DOI: 10.1186/cc5735.

14. Schrier RW, Wang W. Acute renal failure and sepsis. N Engl J Med 2004;351(2):159-169. DOI: 10.1056/NEJMra032401.

15. Lewis JR, Lewis SA. Colistin interactions with the mammalian urothelium. Am J Physiol Cell Physiol 2004;286(4):C913-C922. DOI: 10.1152/ajpcell.00437.2003.

16. Hartzell JD, Neff R, Ake R, Howard R, Olson S, Paolino K, et al. Nephrotoxicity associated with intravenous colistin (colistimethate sodium) treatment at a tertiary care medical center. Clin Infect Dis 2009;48(12):1724-1728. DOI: 10.1086/599225.

17. Pogue JM, Lee J, Marchaim D, Yee V, Zhao JJ, Chopra T, et al. Incidence of and risk factors for colistin-associated nephrotoxicity in a large academic health system. Clin Infect Dis 2011;53(9):879-884. DOI: 10.1093/cid/cir611.

18. Koomanachai $P$, Tiengrim S, Kiratisin P, Thamlikitkul V. Efficacy and safety of colistin (colistimethate sodium) for therapy of infections caused by multidrug-resistant Pseudomonas aeruginosa and Acinetobacter baumannii in Siriraj Hospital, Bangkok, Thailand. Int J Infect Dis 2007;11(5):402-406. DOI: 10.1016/j.ijid.2006.09.011.

19. Sabuda DM, Laupland K, Pitout J, Dalton B, Rabin H, Louie T, et al. Utilization of colistin for treatment of multidrug-resistant Pseudomonas aeruginosa. Can J Infect Dis Med Microbiol 2008;19(6):413-418. DOI: 10.1155/2008/743197.

20. Bagshaw SM, Lapisky S, Dial S, Arabi Y, Dodek P, Wood G, et al. Acute kidney injury in septic shock: clinical outcomes and impact of duration of hypotension prior to initiation of antimicrobial therapy. Intensive Care Med 2009;35(5):871-881. DOI: 10.1007/s00134-008-1367-2.

21. Rocco M, Montini L, Alessandri E, Venditti M, Laderchi A, De Pascale $\mathrm{G}$, et al. Risk factors for acute kidney injury in critically ill patients receiving high intravenous doses of colistin methanesulfonate and/ or other nephrotoxic antibiotics: a retrospective cohort study. Crit Care 2013;17(4):R174. DOI: 10.1186/cc12853.

22. Florescu DF, Qiu F, McCartan MA, Mindru C, Fey PD, Kalil AC. What is the efficacy and safety of colistin for the treatment of ventilatorassociated pneumonia? A systematic review and meta-regression. Clin Infect Dis 2012;54(5):670-680. DOI: 10.1093/cid/cir934.

23. Garzotto F, Piccinni P, Cruz D, Gramaticopolo S, Dal Santo M, Aneloni $\mathrm{G}$, et al. RIFLE-based data collection/management system applied to 
a prospective cohort multicenter Italian study on the epidemiology of acute kidney injury in the intensive care unit. Blood Purif 2011; 31(1-3):159-171. DOI: 10.1159/000322161.

24. Paul M, Bishara J, Levcovich A, Chowers M, Goldberg E, Singer P, et al. Effectiveness and safety of colistin: prospective comparative cohort study. J Antimicrob Chemother 2010;65(5):1019-1027. DOI: 10.1093/ jac/dkq069.
25. Desai K, Kazi M, Ajbani K, Munshi M, Rodrigues C, Soman R, et al Clinical outcomes and safety of colistin in treatment of Gram negative infections: a prospective observational study. Egypt J Crit Care Med 2016;4:67-72. DOI: 10.1016/j.ejccm.2016.07.001.

26. Dewan A, Shoukat M. Evaluation of risk of nephrotoxicity with high dose, extended-interval colistin administration. Indian J Crit Care Med 2014;18(7):427-430. DOI: 10.4103/0972-5229.136070. 